This is a post-peer-review, pre-copyedit version of an article published in Intensive Care of Medicine. The final authenticated version is available online at: http://dx.doi.org/10.1007/s00134-003-2141-0

\title{
ALBUMIN DIALYSIS: A NEW THERAPEUTIC STRATEGY FOR INTOXICATION FROM PROTEIN-BOUND DRUGS
}

\section{Sambit Sen ${ }^{1}$, Lars M. Ytrebø ${ }^{2}$, Christopher Rose ${ }^{3}$, Ole-Martin Fuskevaag $^{4}$, Nathan A. Davies ${ }^{1}$, Geir I. Nedredal ${ }^{2}$, Roger Williams ${ }^{1}$, Arthur Revhaug ${ }^{2}$ \& Rajiv Jalan ${ }^{1}$}

Affiliations

1. Liver Failure Group, Institute of Hepatology, 69-75 Chenies Mews, London, WC1E 6HX, UK

2. Department of Digestive Surgery, University Hospital Northern Norway, Troms $\emptyset$, Norway

3. Department of Cellular Neuroscience, Max-Delbrück Center for Molecular Medicine, Berlin, Germany

4. Department of Clinical Pharmacology, University Hospital Northern Norway, Troms $\varnothing$, Norway

Keywords

Albumin dialysis; Charcoal; Adsorption; Midazolam Fentanyl

AbSTract

Objective Although water-soluble drugs can be removed by haemofiltration/haemodialysis, morbidity and mortality from intoxication with protein-bound drugs remains high. The present study investigates whether albumin dialysis in the form of the Molecular Adsorbents Recirculating System (MARS) is effective in removal of protein-bound drugs.

Design Prospective animal study.

Setting Surgical research laboratory in a university hospital.

Subjects Seven female Norwegian Landrace pigs.

Intervention We studied whether midazolam (97\% albumin-bound) and fentanyl (85\% alpha-1-acid glycoprotein-bound), administered as anaesthetics to pigs with induced acute liver failure, could be removed by MARS dialysis lasting for $4 \mathrm{~h}$.

Measurements After $4 \mathrm{~h}$ of dialysis, total and free anaesthetic concentrations were measured in the blood and dialysate from different segments of the MARS circuit.

Main results Midazolam: total plasma concentrations fell by $47.1 \pm 2.1 \%$ (in $4 \mathrm{~h}$ ) across the MARS filter $(p<0.01)$. The charcoal component of the system reduced the total dialysate drug concentration by $16.4 \pm 2.2 \%(p<0.05)$. Free midazolam removal followed a similar pattern. Fentanyl: total plasma concentrations fell by $56.1 \pm 2.4 \%$ (in $4 \mathrm{~h}$ ) across the MARS filter $(p<0.01)$. Clearance of fentanyl from the dialysate by the charcoal was $70 \pm 0.7 \%$ at $4 \mathrm{~h}(p<0.001)$.

Conclusions The results of the study show that MARS can remove both albumin and other protein-bound drugs efficiently from the plasma, and it may have a place for the treatment of patients suffering from intoxication with this class of compounds. 
This is a post-peer-review, pre-copyedit version of an article published in Intensive Care of Medicine. The final authenticated version is available online at: http://dx.doi.org/10.1007/s00134-003-2141-0

\section{INTRODUCTION}

The Molecular Adsorbents Recirculating System (MARS) is an extracorporeal device that uses the principle of albumin dialysis to remove albumin-bound toxins, and is currently being explored as a liver support system $[1,2,3]$; however, the mechanism of action that makes extracorporeal albumin dialysis useful in liver failure means that this has the potential to remove a wide range of drugs with high albumin binding from the blood. In a recently reported case we demonstrated the efficient removal by MARS of an anti-epileptic drug with $90 \%$ albumin-binding in a patient of phenytoin toxicity [4]. If this applies to other protein-bound substances, the clinical implications would be twofold. Firstly, MARS could be of considerable value in overdose/toxicity with protein-binding substances, which otherwise cannot be efficiently removed from the body. Secondly, when MARS is being used for liver support, it could inadvertently remove drugs (e.g. antibiotics and anti-epileptics), thus lowering their plasma concentration and thereby efficacy, unless the drug dosing is adjusted accordingly.

The effects of MARS therapy on a drug which is strongly albumin-bound in the plasma, may well be different from those on a compound that is protein-bound but not significantly albumin-associated (which one would not expect to be significantly removed). The opportunity to investigate this was provided by a study designed primarily to evaluate the effect of MARS in a porcine model of acute liver failure, where a combination of midazolam (97\% bound to plasma protein, mainly albumin) and fentanyl ( $80-85 \%$ bound to plasma protein, mainly alpha-1-acid glycoprotein) were used to anaesthetise the pigs [5]. The present paper describes changes in the plasma concentrations of the two drugs during the MARS dialysis, and also examines the underlying mechanisms of removal.

\section{MATERIALS AND METHODS}

\section{THE ANIMAL MODEL}

The present study was performed by the international liver failure study group at the Surgical Research Laboratory, University of Troms $\varnothing$, Norway, with the approval of the Norwegian Experimental Animal Board. Seven Norwegian female Landrace pigs, weighing 25-30 kg (mean \pm SEM: $27.1 \pm 0.5 \mathrm{~kg}$ ) were used. The pigs were kept in the animal department for at least 2 days before the experiments, at a temperature of $21 \pm 1^{\circ} \mathrm{C}$, a relative humidity of $55 \pm 10 \%$ and with a 12:12-h light/dark cycle. The animals were fed with Combi Fri chow (Felleskjøpet, Trondheim, Norway) but were fasted overnight prior to the experiment.

Premedication and anaesthesia are described in detail below. The pigs underwent a tracheostomy, were intubated and ventilated $\left(\mathrm{FiO}_{2}=0.5\right)$ on a volume-controlled respirator (Servo 900, Elema-Schönander, Stockholm, Sweden). Tidal volume was adjusted by means of repeated arterial blood gas analyses to maintain $\mathrm{PaCO}_{2}$ between 4.5 and $5.0 \mathrm{kPa}$. Core body temperature was maintained at $38.5 \pm 1^{\circ} \mathrm{C}$ with a heating pad and blankets. All animals received $500 \mathrm{ml} 0.9 \% \mathrm{NaCl}$ containing $625 \mathrm{mg}$ of glucose as a preoperative load in order to prevent any preoperative dehydration. During the experiment, $0.9 \% \mathrm{NaCl}$ was infused at a rate of $3 \mathrm{ml} / \mathrm{kg} / \mathrm{h}$. After the induction of hepatic devascularisation, $50 \%$ glucose and $20 \%$ human albumin (Octapharma, Hurdal, Norway) were continuously infused at rates of 0.60 and $0.66 \mathrm{ml} / \mathrm{kg} / \mathrm{h}$, respectively. A dose of $2500 \mathrm{IU}$ heparin was given intravenously to all pigs at the start of 
This is a post-peer-review, pre-copyedit version of an article published in Intensive Care of Medicine. The final authenticated version is available online at: http://dx.doi.org/10.1007/s00134-003-2141-0

the experiment. Subsequently, heparin was given to keep the activated clotting time (ACT)>100 s. During MARS treatment, additional heparin was given to keep ACT>180 s.

Acute liver failure was induced by an end-to-side porta-caval shunt, along with ligation of the hepatic arteries. The details of the surgery have been described elsewhere [6, 7]. MARS was started $2 \mathrm{~h}$ after the hepatic devascularisation and continued for $4 \mathrm{~h}$ (i.e. until $6 \mathrm{~h}$ post-devascularisation), after which the experiments were terminated with an overdose of pentobarbital and potassium chloride.

\section{ANAESTHESIA}

The pigs were premedicated with an intramuscular injection of ketamine $(20 \mathrm{mg} / \mathrm{kg})$ and atropine $(1 \mathrm{mg}$ ). Anaesthesia was induced with an intravenous bolus of $10 \mathrm{mg} / \mathrm{kg}$ pentobarbital (Pentobarbital; Nycomed Pharma, Oslo, Norway) and $10 \mathrm{mg} / \mathrm{kg}$ fentanyl (Leptanal; Janssen Pharmaceutica, Beerse, Belgium) and maintained during surgery with a central venous infusion of $4 \mathrm{mg} / \mathrm{kg} / \mathrm{h}$ pentobarbital, $0.02 \mathrm{mg} / \mathrm{kg} / \mathrm{h}$ fentanyl and $0.3 \mathrm{mg} / \mathrm{kg} / \mathrm{h}$ midazolam (Dormicum; Roche, Basel, Switzerland). Anaesthesia was stopped after the liver was devascularised. If there were clinical signs of light sedation, small doses of fentanyl and midazolam were given as a bolus. During MARS treatment, the animals were kept sedated by a continuous infusion of $0.04 \mathrm{mg} / \mathrm{kg} / \mathrm{h}$ fentanyl, and $0.6 \mathrm{mg} / \mathrm{kg} / \mathrm{h}$ midazolam, with additional bolus doses given when clinically indicated.

\section{USE OF MARS}

MARS (Teraklin AG, Rostock, Germany; Fig, 1) is an extracorporeal system utilising albumin dialysis which has been described elsewhere [1, 2, 3]. Briefly, it consists of a blood circuit, an albumin circuit, and a renal circuit. Blood is dialysed across an albumin-impermeable high-flux dialysis membrane. The albumin circuit contains $600 \mathrm{ml}$ of $20 \%$ human albumin [i.e. a concentration $(200 \mathrm{~g} / \mathrm{l})$ five to seven times that in the plasma], which passes through the dialysate compartment of the blood dialyser. It subsequently undergoes haemo-filtration/dialysis and passage through activated charcoal and anion exchange resin columns to remove acquired toxins. As the present study was designed to specifically evaluate the role of albumin dialysis in liver failure, haemo-filtration/dialysis was not performed (i.e. no removal of free water or water-soluble toxins), and the relevant ports on the circuit were clamped off. A blood pump (Stöckert Shiley roller pump, Stöckert Instruments, Munich, Germany) was used to run the blood circuit at $150 \mathrm{ml} / \mathrm{min}$, with the albumin dialysate circulated by the MARS pump also at $150 \mathrm{ml} / \mathrm{min}$. 
This is a post-peer-review, pre-copyedit version of an article published in Intensive Care of Medicine. The final authenticated version is available online at: http://dx.doi.org/10.1007/s00134-003-2141-0

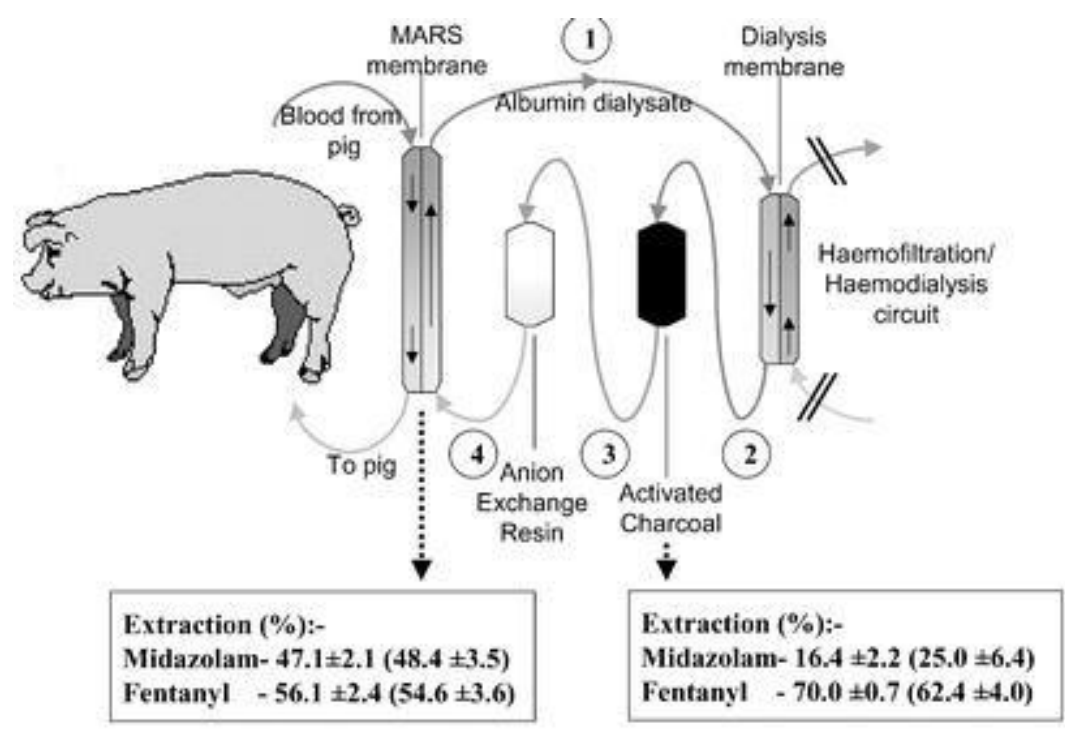

Fig.1 The Molecular Adsorbents Recirculating System (MARS) circuit (with the different segments marked), showing the extraction of midazolam and fentanyl at $4 \mathrm{~h}$ of treatment from the plasma (in the blood filter column) and from the dialysate (by activated charcoal; figures in parentheses are extractions of the free drug)

\section{SAMPLING}

A central venous blood sample was collected at the start of MARS treatment. Four hours after the start, samples were taken from all the different segments of the MARS circuit. Blood samples were collected from the inflow and the outflow segments of the MARS filter. Samples of albumin dialysate were collected from the different segments of the dialysate circuit (segment 1: between blood and haemofilter column; segment 2: between haemo-filter and charcoal column; segment 3: between charcoal and anion exchange resin column; segment 4: between resin and blood column; Fig. 1).

\section{DRUG CONCENTRATION ANALYSIS}

Total and free concentrations of midazolam and fentanyl were measured by high-pressure liquid chromatography (HPLC)-coupled mass-spectrometry.

The HPLC-grade methanol (J.T.Baker, Deventer, Holland), methylclonazepam (F. Hoffmann LaRoche AG, Switzerland), sulphuric acid and chloroform (Merck-Schuchardt, Germany) were used. Water was obtained from a Milli-Q purification system (Millipore, Bedford, Mass.). Standard stock solutions were prepared in methanol (15 $\mu \mathrm{M}$ for fentanyl, $1.5 \mathrm{mM}$ for midazolam), and stored at $-20^{\circ} \mathrm{C}$. Plasma, albumin and normal saline standard samples were prepared by addition of stock solutions.

Before analysis, samples underwent ultrafiltration: $150-\mu 1$ sample was added to Amicon Centrifree (Millipore Bedford, Mass.) tubes and centrifuged $\left(1500 \mathrm{~g}, 12 \mathrm{~min}, 37^{\circ} \mathrm{C}\right)$. The ultrafiltrate was collected and stored for less than 1 week at $-20^{\circ} \mathrm{C}$. For analysis, $100 \mu \mathrm{l}$ of sample was mixed with sulphuric acid $(50 \mu 10.05 \mathrm{M})$, internal standard $(50 \mu \mathrm{l}, 1 \mu \mathrm{M}$ methylclonazepam) and chloroform 
This is a post-peer-review, pre-copyedit version of an article published in Intensive Care of Medicine. The final authenticated version is available online at: http://dx.doi.org/10.1007/s00134-003-2141-0

$(1.5 \mathrm{ml})$. The samples were mixed and then centrifuged $\left(1500 \mathrm{~g}, 5 \mathrm{~min}, 20^{\circ} \mathrm{C}\right), 1 \mathrm{ml}$ of the organic phase transferred to a clean tube and evaporated to dryness under a nitrogen gas stream at $35^{\circ} \mathrm{C}$. The residue was dissolved in 150- $\mu 1$ mobile phase ( $40 \%$ methanol in $5 \mathrm{mM}$ aqueous formic acid). The HPLC was performed on a model 2695 (Waters, Milford, Mass.) separation system with a MS C18 $3.5 \mu \mathrm{m} 2.1 \times 10-\mathrm{mm}$ guard column (Waters); triple quadrupole tandem mass spectrometer, Quattro Micro (Micromass, Manchester, UK); and data system, MassLynx version 3.5 (Micromass). Ionisation mode was positive ion electrospray. Quantitative analysis was performed by multiple reaction monitoring (MRM). Injection volume was 3-8 $\mu$ l with an injection interval of $2.5 \mathrm{~min}$. Autosampler temperature was $10^{\circ} \mathrm{C}$, desolvation gas temperature $300^{\circ} \mathrm{C}$, source temperature $120^{\circ} \mathrm{C}$, desolvation gas flow $600 \mathrm{l} / \mathrm{h}$, cone gas flow $30 \mathrm{l} / \mathrm{h}$, collision gas pressure $4 \times 10^{-3} \mathrm{mBar}$ (argon), and ion energies were set at $1.0 \mathrm{~V}$ for both quadrupoles.

STATISTICAL ANALYSIS

Results are expressed as mean \pm standard error of mean. Student's $t$ test was used to analyse significance of difference between means, and linear regression was used where applicable to determine relationship between variables.

Drug extraction across a filter column was calculated as: Extraction $(\%)=100 \times($ Inflow concentration minus Outflow concentration)/ Inflow concentration.

Drug flux across a filter column was calculated as: Flux $(\mathrm{nmol} / \mathrm{min})=$ Flow rate $\times($ Outflow concentration minus Inflow concentration).

Plasma flow rate through the blood column of the MARS circuit was calculated as follows: Plasma flow rate $(\mathrm{L} / \mathrm{min})=$ Blood flow rate $\times(1$-Haematocrit $)=0.15 \times(1$-Haematocrit $)$.

A value of $p<0.05$ was taken to be statistically significant.

\section{RESULTS}

Plasma total midazolam and fentanyl concentrations at the start of MARS treatment were, respectively, 1074.6 \pm 190.4 and 23.1 $\pm 3.0 \mathrm{nM}$. Since the animals were administered boluses of additional doses of anaesthetic when they exhibited signs of light sedation, the venous plasma concentrations of both drugs (measured from inflowing blood to the MARS system) further increased over the time course of MARS usage at $4 \mathrm{~h}$ (Table 1). 
This is a post-peer-review, pre-copyedit version of an article published in Intensive Care of Medicine. The final authenticated version is available online at: http://dx.doi.org/10.1007/s00134-003-2141-0

Table 1 Concentrations of total and free midazolam and fentanyl (in nM) at MARS in the plasma in the inflow and outflow of Molecular Adsorbents Recirculating System (MARS), and in the albumin dialysate from the different segments of the circuit (segment 1: between blood and haemo-filter column; segment 2: between haemo-filter and charcoal column; segment 3: between charcoal and anion exchange resin column; segment 4: between resin and blood column). Results are expressed as mean \pm SEM. Paired $t$ test was used to test significance of differences between means. Value of $p<0.05$ was regarded as statistically significant

\begin{tabular}{|c|c|c|c|c|}
\hline & \multicolumn{2}{|l|}{ Midazolam } & \multicolumn{2}{|l|}{ Fentanyl } \\
\hline & Total & Free & Total & Free \\
\hline Inflow plasma & $3879.4 \pm 653.5$ & $267.5 \pm 46.9$ & $81.4 \pm 14.4$ & $10.5 \pm 1.8$ \\
\hline Outflow plasma & $2052.3 \pm 362.7$ & $140.8 \pm 30.1$ & $35.6 \pm 6.3$ & $4.5 \pm 0.7$ \\
\hline Dialysate: Seg 1 & $8146.6 \pm 1344.2$ & $135.7 \pm 25.9$ & $57.1 \pm 8.6$ & $6.8 \pm 1.7$ \\
\hline Dialysate: Seg 2 & $8229.6 \pm 1318.0$ & & $53.8 \pm 7.4$ & \\
\hline Dialysate: Seg 3 & $6993.3 \pm 1258.3$ & $97.1 \pm 16.7$ & $16.1 \pm 2.3$ & $2.4 \pm 0.4$ \\
\hline Dialysate: Seg 4 & $6788.3 \pm 1218.5$ & - & $16.4 \pm 2.9$ & - \\
\hline \multicolumn{5}{|l|}{$P$ values } \\
\hline Inflow vs outflow & 0.0007 & 0.0009 & 0.001 & 0.002 \\
\hline Inflow vs seg 1 & 0.001 & 0.002 & 0.01 & 0.05 \\
\hline Seg 2 vs seg 3 & 0.0001 & 0.02 & 0.0002 & 0.01 \\
\hline
\end{tabular}

The MARS system extracted $47.1 \pm 2.1 \%$ of the inflow plasma level of midazolam at $4 \mathrm{~h}$ (Fig. 1; Table 1). Total midazolam concentration in the dialysate (segment 1) was significantly higher than the venous plasma level, with a strong positive correlation between the two ( $r=0.91$, data not shown). The charcoal column was the main site of removal of midazolam from the dialysate. Extraction of total midazolam by charcoal at $4 \mathrm{~h}$ was $16.4 \pm 2.2 \%$. The flux of total midazolam across the MARS system was $-222.6 \pm 37.4 \mathrm{nmol} / \mathrm{min}$ at $4 \mathrm{~h}$, whereas that across the charcoal column was $-185.4 \pm 23.3 \mathrm{nmol} / \mathrm{min}$ (Fig. 2). 
This is a post-peer-review, pre-copyedit version of an article published in Intensive Care of Medicine. The final authenticated version is available online at: http://dx.doi.org/10.1007/s00134-003-2141-0

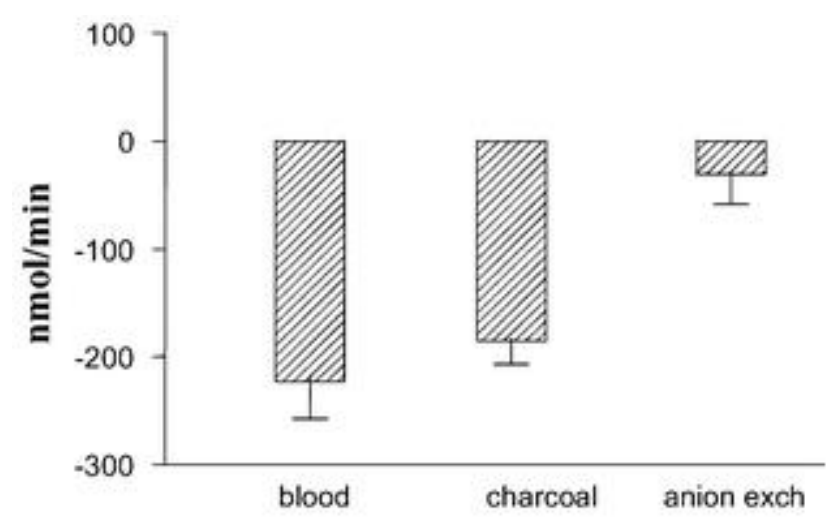

\section{Midazolam}

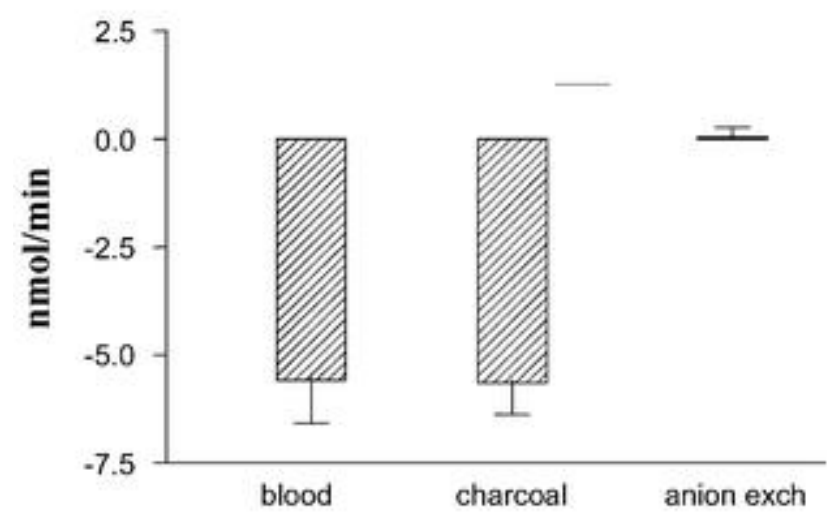

Fentanyl

Fig. 2 The flux of total midazolam and total fentanyl in blood across the MARS circuit, and dialysate across the charcoal and anion exchange resin column, at $4 \mathrm{~h}$ are shown

The extraction of free midazolam by the MARS system was $48.4 \pm 3.5 \%$ of inflow plasma level at $4 \mathrm{~h}$ (Table 1). Dialysate free drug levels (segment 1) were significantly lower than plasma free levels. The free drug extraction across the charcoal column was $25 \pm 6.4 \%$.

There was no significant removal of either the total or free drug across the anion exchange resin.

\section{FENTANYL}

The MARS system extracted $56.1 \pm 2.4 \%$ of fentanyl from the inflow plasma at $4 \mathrm{~h}$ (Fig. 1; Table 1). Total fentanyl concentration in the dialysate (segment 1) was significantly lower than the venous plasma level, and there was a strong positive correlation between the two $(r=0.90$ at $4 \mathrm{~h}$; data not shown). As with midazolam, the charcoal column was the main site of removal of fentanyl from the dialysate, but with a higher extraction (three to four times greater than that for midazolam). Extraction at $4 \mathrm{~h}$ was $70 \pm 0.7 \%$. The flux of total fentanyl across the MARS system was $-5.6 \pm 1.1 \mathrm{nmol} / \mathrm{min}$ at $4 \mathrm{~h}$, and across the charcoal column was $-5.6 \pm 0.8 \mathrm{nmol} / \mathrm{min}$ (Fig. 2). 
This is a post-peer-review, pre-copyedit version of an article published in Intensive Care of Medicine. The final authenticated version is available online at: http://dx.doi.org/10.1007/s00134-003-2141-0

The extraction of free fentanyl by the MARS system from the inflow plasma was $54.6 \pm 3.6 \%$ at $4 \mathrm{~h}$ (Table 1). Dialysate free drug levels (segment 1) were significantly lower than plasma free levels. The free drug extraction by the charcoal column was $62.4 \pm 4 \%$.

There was no significant removal of total or free drug across the anion exchange resin.

\section{DISCUSSION}

The present study investigated the role of albumin dialysis, using MARS, in the removal of two protein-bound drugs, one of which predominantly binds to albumin (midazolam) and one of which does not (fentanyl). Efficient clearance of midazolam (97\% albumin-bound [5]) was not unexpected, and the strong affinity of midazolam for albumin would explain the higher drug concentration observed in the dialysate $(200 \mathrm{~g} / \mathrm{l}$ albumin $)$ compared with that in the venous plasma ( $30 \mathrm{~g} / \mathrm{l}$ albumin $)$. The fact that fentanyl (80-85\% bound to alpha-1-acid glycoprotein [5]) was removed with equal efficacy was of considerable interest and implies that MARS (or albumin dialysis) may have the capacity to remove drugs from binding sites on other plasma proteins. While midazolam was removed against a concentration gradient (dialysate concentration>plasma concentration), plasma fentanyl levels remained higher than those in the dialysate suggesting that it was removed along the concentration gradient.

Both midazolam and fentanyl were primarily cleared from the dialysate by the charcoal filter. This observation is supported by the fact that activated charcoal has the ability to adsorb benzodiazepines [8] as well as opioids [9], and its oral administration has long been used for the treatment of overdoses. Interestingly, the capacity of activated charcoal to remove these drugs from albumin in the dialysate indicates that charcoal hemoperfusion could possibly be an effective therapy for such drug toxicities $[10,11]$.

Considering that fentanyl is not significantly bound to albumin in the plasma, one might have expected a disproportionately large removal of free fentanyl to account for the reduction in total plasma levels; however, as can be seen from Table 1, while MARS resulted in a 55\% extraction of free drug, this cannot account for the total removal of the drug from the plasma. Moreover, analysis of the dialysate showed that $80-90 \%$ of the fentanyl was present in the albumin-bound form. Taken together, these observations imply that fentanyl is removed from the alpha-1-acid glycoprotein in the plasma, and binds to the albumin in the dialysate. Fentanyl is not generally bound to albumin in the plasma, but there are studies showing that it has the capacity to bind to it and also to erythrocytes $[12,13]$. If a fairly constant proportion of the total fentanyl concentration is present in the non-protein-bound free form, it is conceivable that the binding sites on the MARS membrane take up some of the free drug. This in turn would reduce the proportion of free drug present in the plasma leading to release of the protein-bound fentanyl. As the membrane-associated albumin gives up its load of fentanyl to the albumin in the dialysate, the cycle is repeated and an effective concentration gradient established; thus, without actually stripping off fentanyl from alpha-1-acid glycoprotein in the plasma, the effect would be the net removal of fentanyl from the plasma. These data support the hypothesis that only the free drug is actually being removed by the MARS membrane, with constant re-equilibration of the free and bound components in the plasma, without any actual direct removal of the drug from its binding protein by the membrane. 
This is a post-peer-review, pre-copyedit version of an article published in Intensive Care of Medicine. The final authenticated version is available online at: http://dx.doi.org/10.1007/s00134-003-2141-0

The main site of removal of both drugs from the dialysate was the column of activated charcoal. The calculated flux data suggest that this absorption by the charcoal was almost entirely responsible for fentanyl removal from the blood by MARS. In case of midazolam, a higher flux across MARS compared with that across the charcoal column suggests that in addition to charcoal, the membrane/albumin dialysate contributes to an extent in the removal of this highly albumin-bound drug from the blood.

The present study was not designed to look at the kinetics of drug removal, as the pigs had repeated bolus doses of anaesthetics to maintain a stable depth of anaesthesia. The dosage of anaesthetics required during MARS was actually higher than that given during the surgery, most likely due to removal of the anaesthetic agents. Moreover, the drugs were not administered for long enough to achieve steady state; therefore, the drug removal data have been represented as extraction or removal rate at $4 \mathrm{hrs}$ into the MARS session. Despite this weakness, this study indicates that better understanding is required of drug removal in order to make the necessary modifications to the dosage of drugs administered concurrently with MARS treatment. During the use of MARS for liver support, the clinician needs to be aware that it might remove some of the other medications the patient is receiving for therapeutic purposes. In addition to the groups of drugs mentioned above, a large variety of antibiotics are protein-bound (including many which are albumin-bound), as are anti-epileptic drugs. Furthermore, the present study shows that many more drugs (not necessarily bound to albumin) can be removed which may result in sub-therapeutic blood levels. Awareness of this possible side effect should lead to better adjustment of the dosage as well as timing of administration of these drugs.

The results of this study have other clinical implications as well. Both benzodiazepines and opioids are drugs that are commonly used clinically, and can lead to problems related to toxicity or overdosage. In the U.S. alone, in 2001 there were 146 deaths due to benzodiazepine and 173 deaths due to opioid overdose [14]; however, the availability of effective specific antagonists (flumazenil for benzodiazepines and naloxone for opioids) means that in-hospital deaths related to either drug are quite rare, and the role of MARS in the therapy of these specific toxicities is limited. Moreover, removal of the parent drug (e.g. midazolam) might not necessarily mean that active metabolites (e.g. alphahydroxymidazolam glucuronide) are also adequately removed. Rather, one should consider these two drugs as representative of albumin- and other protein-bound drugs that may be effectively removed by albumin dialysis. In the setting of a severe drug toxicity not responding adequately to specific pharmacological antagonists, this might prove to be an effective way of rapidly reducing circulating levels. We have already shown that MARS can effectively clear phenytoin from the plasma in cases of toxicity [4]. Overdosage with other protein-bound drugs, such as verapamil and diltiazem (90 and 80\% plasma protein-bound respectively [5]) which have no effective pharmacological antagonists, are other clinical settings where MARS might be beneficial.

Finally, this study provides the first reliable data describing the mechanism by which extracorporeal albumin dialysis using MARS may act as a therapeutic tool in protein-bound substance toxicity. The results indicate how the system can be modified to improve its efficacy for specific substances. For example, in the case of the drugs described, an improved system could be designed by replacing the anion exchange resin with an additional activated charcoal column. Such future advances might lead to more efficient systems being developed. 
This is a post-peer-review, pre-copyedit version of an article published in Intensive Care of Medicine. The final authenticated version is available online at: http://dx.doi.org/10.1007/s00134-003-2141-0

\section{CONCLUSION}

In conclusion, extracorporeal albumin dialysis using MARS can lead to the efficient removal of both albumin-bound and non-albumin-bound substances from the blood. The mechanism of removal is probably by uptake of the free drug from the plasma, with constant re-equilibration of the free and bound components. The results of this study provide the rationale for exploring the use of extracorporeal albumin dialysis for the treatment of intoxication with protein-bound toxins in appropriately designed trials.

\section{REFERENCES}

1. Stange J, Ramlow W, Mitzner S, Schmidt R, Klinkmann H (1993) Dialysis against a recycled albumin solution enables the removal of albumin-bound toxins. Artif Organs 17:809-813

2. Stange J, Mitzner S, Ramlow W, Gliesche T, Hickstein H, Schmidt R (1993) A new procedure for the removal of protein bound drugs and toxins. Asaio J 39:M621-625

3. Stange J, Mitzner S (1996) A carrier-mediated transport of toxins in a hybrid membrane. Safety barrier between a patients blood and a bioartificial liver. Int J Artif Organs 19:677-691

4. Sen S, Ratnaraj N, Davies NA, Mookerjee RP, Cooper CE, Patsalos PN, Williams R, Jalan R (2003) Treatment of phenytoin toxicity by the Molecular Adsorbents Recirculating System (MARS). Epilepsia 44:265-267

5. Physicians' Desk Reference (2002) 56th edn. Medical Economics, Montvale, N.J.

6. Ytrebo LM, Nedredal GI, Korvald C, Holm Nielsen OJ, Ingebrigtsen T, Romner B, Aarbakke J, Revhaug A (2001) Renal elimination of protein S-100 beta in pigs with acute encephalopathy. Scand J Clin Lab Invest 61:217-225

7. Ytrebo LM, Nedredal GI, Langbakk B, Revhaug A (2002) An experimental large animal model for the assessment of bioartificial liver support systems in fulminant hepatic failure. Scand J Gastroenterol 37:1077-1088

8. Lapatto-Reiniluoto O, Kivisto KT, Neuvonen PJ (1999) Effect of activated charcoal alone or given after gastric lavage in reducing the absorption of diazepam, ibuprofen and citalopram. Br J Clin Pharmacol 48:148-153

9. el-Sayed YM, Hasan MM (1990) Enhancement of morphine clearance following intravenous administration by oral activated charcoal in rabbits. J Pharm Pharmacol 42:538-541

10. Torrente A de, Rumack BH, Blair DT, Anderson RJ (1979) Fixed-bed uncoated charcoal hemoperfusion in the treatment of intoxications: animal and patient studies. Nephron 24:71-77

11. Koffler A, Bernstein M, LaSette A, Massry SG (1978) Fixed-bed charcoal hemoperfusion. Treatment of drug overdose. Arch Intern Med 138:1691-1694

12. Wiesner G, Taeger K, Peter K (1996) Serum protein binding of fentanyl. The effect of postoperative acute phase reaction with elevated alpha 1-acid glycoprotein and methodologic problems in determination by equilibrium dialysis. Anaesthesist 45:323-329

13. Lehmann KA, Schmitz KF, Daub D (1983) Disposition of fentanyl in human blood. Anaesthesist 32:329-334

14. Litovitz TL, Klein-Schwartz W, Rodgers GC Jr, Cobaugh DJ, Youniss J, Omslaer JC, May ME, Woolf AD, Benson BE (2002) 2001 Annual report of the American Association of Poison Control Centers Toxic Exposure Surveillance System. Am J Emerg Med 20:391-452

\section{ACKNOWLEDGEMENTS}

This work was supported by the Liver Research Foundation, the Norwegian Research Council and the Sir Siegmund Warburg Voluntary Settlement. Teraklin AG provided the MARS kits free of cost. 